\title{
Leatherback Sea Turtle Shell: A Tough and Flexible Biological Design
}

\author{
Irene H. Chen ${ }^{1}$, Wen Yang ${ }^{1}$, Marc A. Meyers ${ }^{1,2}$ \\ ${ }^{1}$ Materials Science and Engineering Program, University of California, San Diego, La Jolla, CA 92093, USA \\ ${ }^{2}$ Departments of Nanoengineering and Mechanical and Aerospace Engineering, University of California, San \\ Diego, La Jolla, CA 92093, USA
}

\section{Abstract}

The leatherback sea turtle is unique among chelonians for having a soft skin which covers its osteoderms,. The osteoderm is composed of bony plates that are interconnected with collagen fibers in a structure called suture. The soft dermis and suture geometry enable a significant amount of flexing of the junction between adjacent osteoderms. This design allows the body to contract better than a hard-shelled sea turtle as it dives to depths of over $1,000 \mathrm{~m}$. The leatherback turtle has ridges along the carapace to enhance the hydrodynamic flow and provide a tailored stiffness. The osteoderms are of two types: flat and ridged. The structure of the two types of osteoderms is characterized and their mechanical properties are investigated with particular attention to the failure mechanisms. They both are bony structures with a porous core sandwiched between compact layers that form the outside and inside surfaces. The angle of interpenetration at the suture of osteoderms is analyzed and compared with analytical predictions. The sutures have a triangular shape with an angle of $\sim 30^{\circ}$ which provides a balance between the tensile strength of the osteoderms and shear strength of the collagen fiber layer and is verified by Li-Ortiz-Boyce in a previous study. This is confirmed by an FEM analysis. A calculation is developed to quantify the flexibility of the carapace and plastron as a function of the angular displacement at the sutures, predicting the interdependence between geometrical parameters and flexibility.

Key words: leatherback turtle, suture, mechanical properties, finite element analysis 


\section{Introduction}

A unique type of sea turtle, instead of a hard shell, has a soft shell (leathery-shelled) is called Leatherback sea turtle (Dermochelys coriacea). This type of turtle is the largest chelonian (order of Testudines) and the fourth largest reptile [1]. The northeast coast of Trinidad is the home of the Atlantic leatherback sea turtles, known as 'Matura' [2]. They have been in existence for hundreds of millions of years [3], and there are only a few thousand left on the planet [4]. Thus, they are now critically endangered [5]. Their survival through evolution has brought great interest because of their remarkable attributes. They can grow longer than $2 \mathrm{~m}$ (the maximum length is $2.7 \mathrm{~m}$ ) and can exceed $500 \mathrm{~kg}$ [6]. One characteristic that distinguishes them from other sea turtle species is that they are protected by a leathery skin covering the osteoderms (bony plates) instead of a hard keratinous shell [7]. Their skin feels rubbery, elastic, and stretchable [8]. They are known to dive to a depth of 1,200 meters $[9,10]$, with their deformable body shape enabling some flexibility under high hydrostatic pressure $[11,12]$.

The osteoderms consist of bone-like hydroxyapatite/collagen tissue and their main function is protection [13]; they are connected by a special configuration of interpenetrating extremities called sutures. Two types of osteoderm are found on carapace (dorsal-the back of the animal) and plastron (ventral- belly region of the animal) regions: ridged and flat osteoderms. The sutures enable the carapace to be flexible for expansion during the air intake stage and contraction during deep diving, enabling a larger lung capacity [14]. The osteoderms are located underneath the skin and are connected to a vascular system. The vascular network supports the osteodermal tissue growth. [15].

The flexibility of the turtle shell is provided by the sutures which enable limited relative movement (in plane and out of plane) between the rigid osteoderms. It was found by Li et al. $[16,17]$ that sutures with a periodic triangular waveform have exceptional mechanical functionality in terms of stiffness and strength. The suture in the leatherback turtle provides both interlocking and flexing capabilities. The "suture mechanism" is a method of ensuring 
a prescribed compliance and flexibility to the structure along with mechanical stability and significant tensile strength. The assemblage of rigid elements connected to flexible joints in a zig-zag configuration offers protection from predators because there is no region which the teeth can easily penetrate. It also offers a flexible surface for maneuverability. The suture design also prevents cracks from propagating from one osteoderm to the next; the collagenous interfaces act as crack arresters [18, 19, 20]. Figure 1 shows the hierarchical structure of the leatherback turtle shell with two types of osteoderms (flat and ridged); the osteoderms from the dorsal of the animal, which have a bony ridge, and flat osteoderms. A micro-CT scan of the ridge osteoderm shows the detailed suture. The second type of osteoderm (flat) is found on the dorsal and plastron region of the animal. The micro-CT scan also shows the highly random porous morphology with an interconnecting suture design (in zigzag) between flat osteoderms.

A different type of hard shell turtle, Terrapane Carolina, investigated by Rhee et al. [20] has a sandwich composite structure, composed of two bony layers and a cellular interior with relative porosities of $7 \%$ and $66 \%$, respectively. The corresponding elastic moduli are $\sim 20 \mathrm{GPa}$ and $\sim 1 \mathrm{GPa}$. The shell is compliant and allows small deformations when loaded by low-magnitude forces, and is stiff to counteract larger loads. The tough bony plates provide this balance of properties with flexible and compliant suture which exhibits a viscoelastic response. The flexure strength and modulus of the plastron osteoderms, into which the ribs are engulfed and fused, are $\sim 300 \mathrm{MPa}$ and $\sim 8 \mathrm{GPa}$, respectively. The ribs connected to the osteoderms provide an added stiffening effect. The sutures between red-eared slider turtle osteoderms were found to be weaker in tension than bone but comparatively tough $[21,22$, 23]. Achrai and Wagner [24] found that the keratin surface layer had a profound influence on the fracture energy and increased it by a factor of 2.5-3. The shell integrity was also considerably increased. They developed a synthetic analog to the bone/keratin layered material and obtained a similar increase in toughness and fracture resistance from alumina coated with PVB (poly vynil buthyl) [25]. 
In the leatherback turtle the ribs are not fused to the osteoderms, in contrast with other testudines. This provides additional flexibility to the carapace. There has been considerable work done on the mechanics of rigid turtle shells $[25,26,27]$ but the leatherback turtle has not yet been the object of a structural investigation. In this work, we characterize the structure of the osteoderms and the sutures, in order to understand the toughening mechanisms and evaluate whether the suture geometry in the leatherback turtle is optimized for flexibility and strength.

\section{Materials and Experimental Procedure}

Leatherback turtle shell osteoderms were obtained from the San Diego Natural History Museum and came from a juvenile turtle shell with an approximate length of $\sim 40-50 \mathrm{~cm}$. The skin was first digested by a dermestid beetle colony. Some osteoderms from the carapace have a ridge in the middle with a length of $\sim 40 \mathrm{~mm}$ (along the ridge), width of $\sim$ $20 \mathrm{~mm}$ (across the ridge) and thickness of $\sim 2 \mathrm{~mm}$, while the osteoderms from the plastron region are around $20-25 \mathrm{~mm}$ across. The contents of the osteoderm (water, protein and mineral) were evaluated by treating the samples in a furnace under different conditions and weighing them before and after treatments. The water content was measured by drying the sample for 4 hours at $100{ }^{\circ} \mathrm{C}$. The protein content was measured by heating the osteoderms in a furnace for 24 hours at $400^{\circ} \mathrm{C}$. Structural characterization included X-ray diffraction,

optical microscopy, digital microscopy (Keyence VHX 1000, Itasca, IL, USA) and scanning electron microscopy (SEM, Phillips XL30 SEM, Hillsboro, Oregon, USA). Prior to SEM observation, the samples were coated with iridium. The mechanical behavior (microhardness and compression response) was tested to establish the strength, stiffness, and fracture mechanisms.

\section{$2.1 X$-ray diffraction}

$\mathrm{X}$-ray diffraction (XRD) was performed on the powder collected from ground osteoderm using a bench top XRD system (MiniFlex TM II, Rigaku Company, Austin, Texas). The 
scan was performed continuously from $2 \theta=0$ to $60^{\circ}$, with a step size of $0.01^{\circ}$ at a rate of $1 \%$ min. The radiation source was $\mathrm{CuK} \alpha_{1}$ with wavelength of $0.154 \mathrm{~nm}$.

\subsection{Micro-computerized tomography}

Several osteoderms from the plastron and one from the carapace were imaged using a micro-computed tomography Skyscan 1076 scanner (Bruker-MicroCT, Kontich, Belgium). An isotropic voxel size of $36 \mu \mathrm{m}$, an electric potential of $50 \mathrm{kVp}$, and a current of $200 \mu \mathrm{A}$ were applied during scanning using a $0.5 \mathrm{~mm}$ aluminum filter with a rotation step of $0.7^{\circ}$ and exposure time of $110 \mathrm{~ms}$. A beam hardening correction algorithm was applied during image reconstruction.

\subsection{Mechanical testing}

Forty compression samples were cut using a diamond blade across the keel (against the keel orientation) creating 5-7 rectangular strips (length of $2 \mathrm{~cm}$ and width of $2 \mathrm{~mm}$ ) and again using a diamond blade to cut into dimensions of approximately $2 \times 2 \times 2 \mathrm{~mm}$ cubic structures. The test samples were prepared in such a way to preserve the sandwich structure through the thickness direction. After being cut to roughly the correct dimensions, samples were polished to accurately produce samples of the desired dimensions, using 180\#-4000\# silicon carbide papers and alumina powder. Before testing, the samples were immersed in Hanks balanced salt solution (HBSS) for at least 24 hours. Uniaxial compression tests were conducted using a 30kN load cell in an Instron 3342 testing machine (Instron, Norwood, MA) at a strain rate of $10^{-3} \mathrm{~s}^{-1}$. Three loading orientations were applied: axial (throughthickness), longitudinal (along the ridges) and transverse (perpendicular to the ridges). The compression tests were conducted immediately after removing the samples from the HBSS. All the samples were tested at room temperature. To understand the toughening mechanisms of the shell, loading-unloading-reloading compressive tests were performed. To see the damage of the sample including the generation and propagation of the cracks and the interaction between the crack, pores as well as the bony structure, the well pre-polished lateral surfaces of the samples were observed using SEM after each unloading. 


\section{Results and Discussion}

\subsection{Microstructure and composition of osteoderm}

Similar to the red-eared slider turtle [22], the osteoderm of the leatherback sea turtle has a multi-scale hierarchical structure (Fig. 1). Two types of osteoderms are found on the animal:

(1) Ridge osteoderms (one shown in Fig.1b) on the dorsal regions of the animal. The leatherback turtle has five ridges on its back. In addition to the five dorsal ridges, there are two ridges along the margins [1]. The micro-CT scan (Fig.1c) of the ridge osteoderm shows individual sutures standing out and giving a 3D layering effect. The tissue observed at a high magnification is granular (Fig 1d).

(2) Flat osteoderms (Fig. 1e) from the plastron. The micro-CT scan also shows a highly porous structure in the flat osteoderms (Fig. 1f). The edges of these osteoderms have suture structures (zig-zag pattern).

Figure $1 \mathrm{~g}$ shows the tooth-like suture $\left(2 \theta=30^{\circ}\right)$ with the counterpart intrusions in the neighboring osteoderm. Here, $2 \theta$ is the suture angle. The osteoderm is a mineralized tissue with a smooth surface in contrast to the regions between the sutures which consist of a nonmineralized collagen fibrous structure shown in Fig. 1h.

The region between the sutures contains collagen fibers which connect adjoining osteoderms. The suture area is slightly depressed $(\sim 300 \mu \mathrm{m}$ below the highest portion $)$ in comparison with the remainder of the osteoderm. The inter-suture space (separation between adjoining osteoderms) is approximately 100-200 $\mu \mathrm{m}$. The extra space allows the suture to be flexible and compliant when subjected to flexure caused, inter alia, by external pressure. Figure 2 shows that the mineral in the osteoderms is identified as hydroxyapatite according to matching the peaks from the library of diffraction data. The principal contents of the leatherback osteoderms are $\sim 66 \mathrm{wt} \%$ mineral, $\sim 21 \mathrm{wt} \%$, water, and $\sim 13 \mathrm{wt} \%$ protein- 
related content. This value compares well with measurements by the Achrai and Wagner on the red-eared turtle $(10 \pm 4 \mathrm{wt} \%$ protein) [24].

\subsection{Geometry of osteoderm suture: analysis of failure mechanisms}

Figure 3 shows the typical suture tooth angles. Each tooth interlocks with two counterparts on the adjoining osteoderm. The average tooth angle is $\sim 30^{\circ}$ and has a width at the base (amplitude) of $\sim 1 \mathrm{~mm}$ (average of 10 samples). Four types of suture geometries have been identified in nature [16, 17]: trapezoidal; anti-trapezoidal; triangular; and rectangular. Two types of suture tooth geometries are presented in Fig. 4a: triangular and trapezoidal teeth. For both cases, the half-angle of the suture is defined as $\theta$. Thus, the angle of the suture is $2 \theta$ for the triangular case. For the general trapezoidal suture $\left(0^{\circ}<2 \theta<90^{\circ}\right)$, there are flat segments at the extremities. For the limiting case of $2 \theta=90^{\circ}$ the sutures become rectangular. Parameters that describe the geometry are defined here for the triangular and rectangular cases.

Li et al. [16] postulated two suture failure mechanisms in tension: (a) tooth failure, which occurs on the tooth (mineral-brittle failure) and (b) interfacial failure which occurs between the teeth (collagen-ductile failure). These two types of failure are shown schematically in Figure 4b. Figure $4 \mathrm{a}$ displays the configuration for triangular and rectangular teeth. For triangular teeth, the two failure modes will be quantitatively estimated as a function of angle 20. A more evenly distributed stress field is produced for the triangular shape, therefore providing more efficiency in load transmission, stiffness, strength, energy absorption and fatigue over the rectangular shape. A uniaxial normal external traction $\sigma_{\mathrm{Ap}}$, generates a stress state characterized by $\sigma_{11}, \sigma_{22}$ and $\tau$, acting on a unit cube making an angle of $\theta$ with the tensile axis; this is shown in Fig. 4c . The shear stress is [16]:

$$
\tau=\sigma_{A p} \sin \theta \cos \theta
$$


The normal stresses are not used in the first order calculation applied here. Their values can be obtained in a similar fashion and are: $\sigma_{11}=\sigma_{A p} \cos ^{2} \theta ; \sigma_{22}=\sigma_{A p} \sin ^{2} \theta$. The shear stress can also be expressed as:

$$
\frac{2 \tau}{\sigma_{A p}}=\sin 2 \theta
$$

The procedure developed by $\mathrm{Li}$ et al. $[16,17]$ will be followed here. Three parameters define the geometry (shown in Fig. 4a): the interface thickness (measured horizontally) $g$; the wavelength $\lambda$; and the amplitude $A$. These determine the angle $\theta$ for the triangular tooth and skeletal volume fraction $f_{v}=(\lambda-2 g) / \lambda$ for the triangular tooth. The parameter $f_{v}$ increases toward 1 as $g$ decreases. The angle $\theta$ is given by [16]:

$$
\tan \theta=\frac{\lambda-2 g}{2 A}
$$

For the rectangular case (the extreme case of trapezoidal teeth) a virtual angle $\theta$ is defined by Li et al. [16] by the same Equation 3, using parameters from Fig. 4a. . In this case, $\theta$ is given by $\tan \theta=f v \lambda / 2 A$ and $\beta$ is zero according to the definition by Ortiz's group $[16,17]$.

For the triangular teeth, the shear stress along the interface is found to be constant; so are the normal stresses. Such is not the case for the rectangular teeth, where the shear stresses are higher at the ends. The shear lag model is necessary to compute these stresses. Assuming a tensile failure stress of $\sigma_{f}$ for the tooth and a shear strength of the interface equal to $\tau_{f}$, the critical values are found to vary with $\theta$ according to Equation 2 and as shown in the failure map of Figure $4 \mathrm{~b}$. The line indicates the boundary between interfacial and tensile failure. For values of $2 \tau_{f} / \sigma_{f}$ above the boundary, failure occurs by tooth failure; for values below, interfacial shear failure dominates. The critical values are dependent on $\theta$ and increase from 0 to 1 [16]. For the rectangular teeth, the shear lag model predicts the variation of $\tau$ along the side, and the corresponding expression is: 


$$
\tau_{f}=\frac{\sigma_{f}}{2 A}\left(\frac{\lambda-2 g}{2}\right)
$$

This leads to:

$$
\frac{2 \tau_{f}}{\sigma_{f}}=\tan \theta
$$

This relationship is also plotted in Figure $4 \mathrm{~b}$ and the corresponding line falls below that for the triangular teeth.

It is possible to estimate the tensile strength of the osteoderms from values for compact bone by making an adjustment for its porosity based on the Gibson-Ashby [30] equation relating the fracture strengths of compact and porous bone as a function of the density $\rho$ :

$$
\frac{\sigma_{f}}{\sigma_{0}}=C\left(\frac{\rho}{\rho_{0}}\right)^{3 / 2}
$$

where the values with subscript 0 refer to ideal fully dense bone and $\mathrm{C}$ is a parameter that is approximately equal to 0.3 . The osteoderm is porous (porosity is $1-\rho / \rho_{0}=0.4$ ). However, compact bone has some porosity due to the Haversian system. The tensile strength of compact bone is $\sigma_{0} \sim 150 \mathrm{MPa}$. Assuming that it has a porosity of 5\%, and using Eqn. 6, we can compute the tensile strength of an ideal 100\% dense bone: $\sigma_{0} \sim 600 \mathrm{MPa}$.

The tensile strength obtained by applying this parameter to Eqn. 6:

$$
\sigma_{f}=84 \mathrm{MPa}
$$

This value is consistent but slightly higher the compressive strength along the thickness direction, as seen in Figure 8, is $\sim 60 \mathrm{MPa}$. This is due to the uncertainty in the porosity of compact bone, which was assumed to be $5 \%$. We will consider, to a first approximation, the tensile strength equal to $60 \mathrm{MPa}$, although we know that there is a certain difference between tensile and compressive strength in bone.

The shear strength of the interface can be estimated from the tensile strength of collagen. Reported values vary and we will use here the shear strength quoted by Chen et al. [29] for 
the armadillo Sharpey's fibers: $18 \mathrm{MPa}$. This is close to the value of $20 \mathrm{MPa}$ provided by Li et al.[16]. Thus, the ratio is:

$$
\frac{2 \tau_{f}}{\sigma_{f}}=\frac{36}{60}=0.6
$$

From Figure $4 \mathrm{~b}$ and Eqn. 2 one obtains $2 \theta=36^{\circ}$. This value is consistent with the tooth angle observed in the current experiments $\left(2 \theta \sim 30^{\circ}\right)$ and it can be concluded that the triangular teeth take full advantage of both the tensile strength of bone and interface strength of collagen.

The plot in Fig. 4b shows separate regions of "tooth failure" and "interfacial shear failure". The two distinctive regions of tooth failure and interfacial shear failure divided by the two lines: triangular suture (red solid) and trapezoidal suture (green dashed). The region above the line corresponds to "tooth failure" and the one below to "interfacial shear failure". Due to the nature of the suture geometry, the triangular suture has a greater interfacial shear failure region than the trapezoidal suture and correspondingly a smaller tooth failure region.

Figure 5a shows the CT scan of an individual ridged osteoderm. The tridimensional nature is evident and the simple two-dimensional analysis presented ealier is a simplification. There are clear protrusions, which should correspond to intrusions in the matching surface. The separation between adjacent osteoderms is seen in more detail in the CT scan of Figure 5b. This separation is larger than the one for the red-eared slider turtle, measured by Achrai and Wagner [23]. This larger separation enables a greater flexibility which is connected to the ability of the leatherbsack turtle to dive to great depths.. Figure 5c shows a schematic representation of the sutures protruding from the lateral part of the structure and forming a 3D layering effect (Fig.5b). The sutures are represented as individual pyramids to provide a more secure interlocking method in three dimensions (Fig. 4). Figure 6 shows the fracture of the collagen fibers at the suture after two osteoderms are pulled apart. The collagen fibers 
enable flexibility in the connections of the osteoderms. Several fractured collagen fibers can be seen and are marked by arrows.

\subsection{Finite element simulation of suture design}

Li et al.[17] also developed a general linear elastic formulation, comparing trapezoidal (and anti-trapezoidal), triangular, and rectangular sutures. This analysis was compared with an in-depth FEM evaluation. A much simpler FEM analysis is conducted here to verify the importance of the angle $2 \theta$ on the stresses developed in the bony matrix and collagen fibers. The bone is considered as a linear isotropic solid with $\mathrm{E} \sim 1 \mathrm{GPa}$ and $v \sim 0.17$. The use of $\mathrm{E}=1$ $\mathrm{GPa}$ is justified by compression tests and from the use of the Gibson-Ashby equation [30] for the elastic modulus of a porous material:

$$
\frac{E}{E_{0}}=C_{1}\left(\frac{\rho}{\rho_{0}}\right)^{2}
$$

The parameter $C_{1}$ is approximately equal to 1 . The Young's modulus for compact bone (zero porosity) is $E_{0} \sim 10 \mathrm{GPa}$. Using a ratio of densities equal to 0.4 , one obtains $E=1.6$ GPa.

The connecting collagen fibers are modeled with the Ogden constitutive equation [32, 33] which describes the response of a non-linear hyper-elastic material $(\mu \sim 0.11 \mathrm{GPa}$ and $\alpha \sim 26)$, where $\varepsilon+1$ is the extension ratio, and $\varepsilon$ is the uniaxial strain.

$$
\sigma=\frac{2 \mu}{\alpha}\left((\varepsilon+1)^{\alpha-1}-(\varepsilon+1)^{-1-\frac{\alpha}{2}}\right)
$$

Figure 7 shows three sutures with $2 \theta=30^{\circ}, 60^{\circ}$, and $90^{\circ}$; one tooth and the counterpart intrusion are represented. The modeling (Abaqus FEM code) used quadrilateral elements in plane strain. Thus, the lateral dimensions (along y direction) remain constant while the extremities along $\mathrm{x}$ direction are subjected to tension. A tensile traction of $\sim 12 \mathrm{MPa}$ was applied along the $\mathrm{x}$-direction. Figures $7 \mathrm{a}-\mathrm{c}$ indicate the higher stress concentrations, 
delineated at the tooth tips as red/orange/yellow. The region between suture (blue) corresponding to the collagen shows a lower stress field due to its different mechanical properties. The von Mises stresses are plotted along the symmetry axis of the simulation in Fig. 7d. The FEM simulations of Fig. 7a-c and the plot of Fig. 7d show that the stresses in the collagen are much lower than in the bony extremities. They drop from $12 \mathrm{MPa}$ to less than $1 \mathrm{MPa}$ along the center line. In the edges of the bony component, the von Mises stress rises up to $18 \mathrm{GPa}$, in places. The results show, in clear fashion, that the stresses in the organic (collagenous) component rise with angle $2 \theta$. For $2 \theta=30^{\circ}$, they are $\sim 1 \mathrm{MPa}$; for $2 \theta$ $=90^{\circ}$, they rise to $\sim 8 \mathrm{MPa}$. Thus, a smaller angle is advantageous, since it decreases the stresses in the weaker organic suture material.

\subsection{Mechanical properties and damagemechanisms of osteoderm}

The band plots in Fig. 8 show the individual compressive stress-strain curves and their approximate range. In orientation $\mathrm{A}$, the curves have a small linear elastic region followed by a decrease in the slope of the stress-strain response. This second region corresponds to the failure and internal buckling of the larger voids in the porous region. There is also collagen sliding activity like in other mineralized biological materials. However, the leatherback turtle shell has a lower fraction of collagen fibers in the osteoderms than skeletal bone and therefore the 'plasticity' is reduced. For orientations B and $\mathrm{C}$, one cannot distinguish a linear region, and the slope decreases monotonically with strain from the onset of loading. For these configurations, the interfaces between dense and porous bone are parallel to the loading direction.

The Weibull distribution of compression strengths (maximum in the stress strain curve) in the three orientations is shown in Figure 9. At 50\% probability of failure, the compressive strengths in Orientations $\mathrm{A}, \mathrm{B}$, and $\mathrm{C}$ are $63 \mathrm{MPa}(\mathrm{m}=4.07), 27 \mathrm{MPa}(\mathrm{m}=$ 1.69), and $16 \mathrm{MPa}(\mathrm{m}=2.23)$, respectively. The parameter $\mathrm{m}$ is determined from the slope of the curve fit. Orientation $\mathrm{A}$ is the strongest which is expected, since this is the direction at 
which external predators apply the force through their teeth, causing either crushing or perforation. A biting action will apply compression perpendicular to the carapace surface. Since the pore distribution has no apparent anisotropy, there is not much of difference in the compressive strengths of OB (longitudinal) and OC (transverse), compared to that of OA.

Figure 10 shows a characteristic sequential loading-unloading-reloading of a sample for orientation A. Six tests were performed with consistent results. These sequential loadingunloading experiments had two objectives: to establish the decrease in Young's modulus and to observe the damage in specimens after unloading. The Young's measured from the stress-strain curves is retained at the $2^{\text {nd }}$ loading cycles, changing only marginally from 1.08 to $1.04 \mathrm{GPa}$. However, at the $3^{\text {rd }}$ loading cycle, there is significant decrease in stiffness, to $\sim 0.84 \mathrm{GPa}$. The permanent strain upon unloading and reloading is $2 \mathrm{pct}$. This means that the microstructure is essentially unchanged. It can be seen that the curves in the first loading deviate only slightly from linearity; there is evidence for pore collapse, corroborated by SEM (Fig. 11). However, upon loading up to $14 \mathrm{MPa}$ (the second reloading stage), the residual strain, upon unloading, is 5 pct. When the specimen is reloaded, the Young's modulus is reduced to $0.84 \mathrm{GPa}$. This means that at $14 \mathrm{MPa}$, significant damage to the microstructure was done, resulting in the decrease in Young's modulus. The $3^{\text {rd }}$ loading appears to introduce damage into the structure as evidenced by the significant decrease in stiffness.

Figure 11 illustrates the damage mechanisms that were identified before and after $1^{\text {st }}$ and $2^{\text {nd }}$ cycles of compression: (1) crack re-alignment (Fig. 11a,b); (2) narrowing of the microcracks perpendicular to the loading direction (Fig. 11a,b); (3) microcrack closure through compression (Fig.11a,b) ; (4) crack opening after the second compression (Fig. 11cd). These observations complement the compressive tests shown in Fig. 10.

\subsection{Carapace and plastron flexibility}


The larger deflection of the carapace and plastron in comparison with other turtles is the result of: (a) the dermal layer is not keratinized but is soft and is therefore significantly more flexible; (b) the relative small size of the osteoderms with respect to the carapace. Vernerey and Barthelat [34-36] developed an analytical method to describe how the individual scales or plates of an articulating structure contribute to its total curvature. These equations were specifically designed with a focus on the scales of fish and incorporating the individual bending of scales in addition to the flexibility of the junctions. A simpler expression is presented here, using rigid osteoderms as units.

The angle between the two connected osteoderms when bending is applied to a segment of the plastron is shown in Fig. 12a; the maximum angular deflection between two osteoderms, denoted as $\alpha$, is shown. This value can be as high as $37^{\circ}$. Three osteoderms connected by collagen were first saturated in water and then manually forced to deform in flexure until the stiffness increased significantly. Figure $12 \mathrm{~b}$ shows in schematic fashion how the collagen fibers are stretched upon deflection.

By assuming a sequence of osteoderms connected through sutures, it is possible to estimate the maximum radius of curvature $\rho$, and the ratio between the maximum deflection $\delta$ and carapace length L. This is shown in Figure 13a. The curvature of a beam, $\rho$, is related to the deflection $v$ by [29]:

$$
\frac{1}{\rho}=\frac{\frac{d^{2} v}{d x^{2}}}{\left[1+\left(\frac{d v}{d x}\right)^{2}\right]^{3 / 2}}
$$

The radius $\rho$ is the inverse of curvature. For small deflections this term can be neglected:

$$
\left(\frac{d v}{d x}\right)^{2}<<1
$$

In our case, the angle $\alpha$ is small (less than $15^{\circ}$ ) and this approximation can be made: 


$$
\frac{1}{\rho} \cong \frac{d^{2} v}{d x^{2}}=\frac{\Delta}{\Delta x}\left(\frac{v}{l}\right)
$$

where $l$ is the length of an osteoderm and $v$ is the maximum deflection that it allows.

The flexibility of an array of osteoderms can be defined by the parameter $\delta / L$, where $\delta$ is the maximum deflection and $L$ is the length of the carapace (Fig. 13a).

We assume constant angular deflections $\alpha$ in each osteoderms. The carapace will exhibit, instead of a circular shape, a sequence of segments of length $l$ that follow a trajectory with an approximate radius of curvature $\rho$ (Fig. 13a). The total length of the turtle (carapace or plastron) being $L$, the number of osteoderms is $n=L / l$.

The deflection angle $\alpha$ is equal to the central angle BOD. This can be shown by considering the circle passing through the extremities of the segments and tracing tangents to it at B and D. These tangents make the same angle $\alpha$ and it can be shown by simple geometry that the angle $\mathrm{BOD}=\alpha$.

The following relationship connects $\theta$ and $\alpha$ :

$$
\theta=n \alpha=\frac{L \alpha}{l}
$$

where $\theta$ and $\alpha$ are expressed in radians. In order to obtain the total deflection $\delta$ one needs to consider the triangle OAC:

$$
\delta=\rho-\rho \cdot \cos \frac{\theta}{2}
$$

When $\alpha$ is small, we can assume that the length of the circular segment is equal to $l$. Thus:

$$
l=\alpha \rho
$$

Substituting Eqns. 14 and 16 into Eqn. 15:

$$
\frac{\delta}{L}=\frac{1}{\alpha}\left(\frac{l}{L}\right)\left[1-\cos \left(\frac{\alpha}{2} \cdot \frac{L}{l}\right)\right]
$$


Equation 17 predicts the normalized deflection of plastron or carapace of a turtle as a function of the angular deflection $\alpha$ at each osteoderm and of the number of osteoderms $n=L / l$. Figure $13 \mathrm{~b}$ shows the variation of normalized deflection with $\alpha$ for different values of $\mathrm{n}=5,10,15,20$, and 25 . It is clear that the deflection increases monotonically with $\alpha$. For a constant $\alpha$, the deflection increases with the number of osteoderms $n=L / l$ in the carapace or plastron. This explains the greater flexibility exhibited by the leatherback turtle $(n \sim 20)$ in comparison with the red-ear slipper turtle ( $\mathrm{n} \sim 5)$.

\section{Conclusions}

(1) The leatherback sea turtle has a unique carapace and plastron that provide sufficient flexibility for deep diving (over 1,000 m, generating a pressure of $\sim 10 \mathrm{MPa}$ ). This enables the ability for the shell to accommodate the change in volume of the lungs. Upon diving, the volume of the lungs decreases because the air is compressed to pressures that are equal to $1 \mathrm{~atm}(=100 \mathrm{~Pa})$ for every $10 \mathrm{~m}$ of depth. Thus, the decrease in space between the plastron and carapace, as the leatherback turtle descends, accommodates the collapse of the lungs.

(2) The flexibility is enabled by a carapace with triangular sutures in which the angle of the teeth in the osteoderms is approximately $30^{\circ}$. Additionally, the carapace and plastron are not covered by rigid keratin, as is the case for most turtles, but by a flexible dermis.

(3) We show that the junction of adjacent osteoderms is accomplished by a suture design which consists of a 3D interpenetrating mechanism providing flexibility. This design is more complex than the conventionally known $2 \mathrm{D}$ geometry and is highly effective in providing both flexibility and protection against predator teeth, since the entire organism is covered with a bony layer. An analysis is performed based on the Li-Ortiz-Boyce theory showing that the angle the sutures $2 \theta=30^{\circ}$, is well suited for the optimization of the tensile strength. 
(4) Repeated compression tests with reloading show that the failure is gradual and that the retardation of the fracture of the mineral is effected by the collagen fibers embedded in the bony structure, providing toughness to the osteoderms.

(5) The compressive strength is anisotropic, with the highest value ( 60 MPa) reached when loading is applied perpendicular to the plane of the suture. In this loading orientation the sandwich structure operates fully. When loading is applied either longitudinally or transversely, in the plane of the osteoderms, the mean strength is considerably lower, $30 \mathrm{MPa}$.

(6) The ability of the carapace and plastron to flex is evaluated by means of a flexibility parameter, which is the maximum deflection divided by the length. It is proposed that the smaller osteoderm/length ratio for the leatherback turtle provides an increased ability to flex.

\section{Acknowledgement}

Dr. Brad Hollingsworth, Curator at The Natural History Museum, kindly provided us with leatherback sea turtle osteoderms from a juvenile specimen. His considerate help enabled this research program. We thank CalIT ${ }^{2}$ (Ryan Anderson) for SEM and SIO (Prof. G. Arrhenius) for XRD. We also acknowledge the help received by Maribel Lopez, Everett Chris, Vincent Sherman, and Bin Wang. This research was partially funded by the National Science Foundation (Grant Number: DMR-1006931), by the UC Labs Program (Grant number: 12-LR-239079), and by Multi-University Research Initiative through the Air Force Office of Scientific Research (AFOSR-FA9550-15-1-0009).

\section{References}

[1] Wyneken, J. 2001. The Anatomy of Sea Turtles. U.S. Department of Commerce NOAA Technical Memorandum NMFS-SEFSC-470, 1-172 pp.

[2] Safina C. Voyage of the Turtle: In Pursuit of the Earth's Last Turtle. New York: Henry Holt and Company; 2006. 
[3] Wood RC, Johnson-Give J, Gaffney ES, Maley KF. Evolution and phylogeny of the leatherback turtles (dermochelyidae), with descriptions of new fossil taxa. Chelon Conserv Biol 1996; 2: 266-286.

[4] Spotila J, Reina R, Steyermark AC, Plotkin PT, Paladino FV. Pacific leatherback turtles face extinction. Nature Mater 2000; 405: 529-551.

[5] Crowder L. Leatherback's survival will depend on an international effort. Nature Mater 2000; 405: 881.

[6] Wood G. The Guinness Book of Animal Facts and Feats. New York: Sterling Pub Co Inc; 1983

[7] Magwene PM, Socha JJ. Biomechanics of turtle shells: How whole shells fail in compression. J Exp Zool 2013; 319: 86-98.

[8] Eckert KL, Luginbuhi C. Death of a giant. Marine Turtle Newsletter 1988; 43: 2-3.

[9] Houghton JDR, Doyle TK, Davenport J, Wilson R P, Hays GC. The role of infrequent and extraordinary deep dives in leatherback turtles (Dermochelys coriacea). J Exp Biol 2008; 211: 2566-2575.

[10] Milagros LM, Rocha CFD, Wallace ADBP, Miller P. Prolonged deep dives by the leatherback turtle Dermochelys coriacea: pushing their aerobic dive limits. Marine Biodiver Rec 2009; 2: 2-3.

[11] Murphy C, Kelliher D, Davenport J. Shape and material characteristics of the trachea in the leatherback sea turtle promote progressive collapse and reinflation during diving. $\mathrm{J}$ Exp Biol 2012; 215: 3064-71.

[12] Fossette S, Gleiss AC, Myers AE, Garner S, Liebsch N, Whitney N, Hays GC, Wilson RP, Lutcavage ME. Behaviour and buoyancy regulation in the deepest-diving reptile: the leatherback turtle. J Exp Biol 2010; 213: 4074-4083.

[13] Yang W, Chen IH, Gludovatz B, Zimmermann EA, Ritchie RO, Meyers MA. Natural flexible dermal armor. Adv Mater 2013; 25: 31-48.

[14] Eckert SL, Eckert KL, Ponganis P, Kooyman GL. Diving and foraging behavior of leatherback sea turtles (Dermochelys coriacea). Canad J of Zool 1989; 67: 2834-40. 
[15] Davenport J, Plot V, Georges JY, Doyle TK, James MC. Pleated turtle escapes the box - shape changes in Dermochelys coriacea. J Exp Biol 2011; 214: 3474-3479.

[16] Li Y, Ortiz C, Boyce MC. Stiffness and strength of suture joints in nature. J Amer Phys Soc 2011; 84: 1-5.

[17] Li Y, Ortiz C, Boyce M., A generalized mechanical model for suture interfaces of arbitrary geometry. J Mech Phys Solids 2013; 61: 1144-67.

[18] Hubbard RP, Melvin JW, Barodawala, IT. Flexure of cranial sutures. J Biomech 1971; 4: 491.

[19] Jaslow CR. Mechanical properties of cranial sutures. J Biomech 1990; 23: 313.

[20] Jasinoski S, Reddy BD, Louw KK, Chinsamy A. Mechanical of cranial sutures using finite element method. J Biomech 2010; 43: 3104-3111.

[21] Rhee H, Horstemeyer MF, Hwang Y, Lim H, El Kadiri H, Trim W. A study on the structure and mechanical behavior of Terrapene carolina carapace: A pathway to design bio-inspired synthetic composites. Mater Sci Eng C 2009; 29: 2333-2339.

[22] Krauss S, Mosonego-Ornan E, Zelzer E, Fratzl P, Shahar R. Mechanical Function of a Complex Three-Dimensional Suture joining the Bony Elements in the Shell of the RedEared Slider Turtle. Adv Mater 2009; 21: 407-412.

[23] Achrai B, Wagner HD. Microstructure and mechanical properties of the turtle carapace as a biological composite. Acta Biomater 2013; 9: 5890-5902.

[24] Achrai B, Benny BO, Wagner HD. Bending mechanics of the red-eared slider turtle carapace. J Mater Behav Biomed Mater 2013; 30: 223-233.

[25] Achrai B, Bar-On B, and H DWagner HD. Biological armors under impact-effect of keratin coating, and synthetic bio-inspired analogues. Bioinspir Biomim 10 (2015) 016009.

[26] Balani K, Patel RR, Kershri AK, Lahiri D, Agarwal A. Multi-scale hierarchical of helydra serpentine: microstructure and mechanical properties of turtle shell. J. Mech Behav Biomed Mater 2011; 4: 1440-51.

[27] Xu Y, Zhang L. Mechanical properties and microstructure of tortoise shell. Compos 1995; 26: 315-8. 
[28] Damiens R, Rhee H, Hwang Y, Park SJ, Hammi Y, Lim H. Compressive behavior of a turtle's shell: experiment, modeling and simulation. J Mech Behav Biomed Mater 2012; 6: 106-12.

[29] Popov EP. Engineering mechanics of solids. New Jersey: Prentice Hall, 1999. p 584.

[30] Gibson LJ, Ashby MF. Cellular solids: Structure and properties. New York: Cambridge University Press; 1999.

[31] Chen IH, Kiang J, Lopez MI, Chen PY, McKittrick J, Meyers MA. Armadillo armor: Mechanical testing and micro-structural evaluation. J Mech Behav Biomed Mater 2009; 4:713-722.

[32] Ogden RW, Proceedings of the Royal Society of London. Series A, Mathematical and Physical Sciences, 1972; 326: 565-584.

[33] Meyers MA, Chen, PY. Biological Materials Science, Cambridge U Press, 2014, p. $355,356$.

[34] Vernerey FJ, Barthelat F. Skin and scales of teleost fish: Simple structure but high performance and multiple functions Journal of the Mechanics and Physics of Solids 2014;68:66-76.

[35] Vernerey FJ, Barthelat F. On the mechanics of fishscale structures International Journal of Solids and Structures 2010;47:2268-75.

[36] Vernerey FJ, Musiket K, Barthelat F. Mechanics of fish skin: A computational approach for bio-inspired flexible composites. International Journal of Solids and Structures 2014;51:274-83. 


\section{Figures}

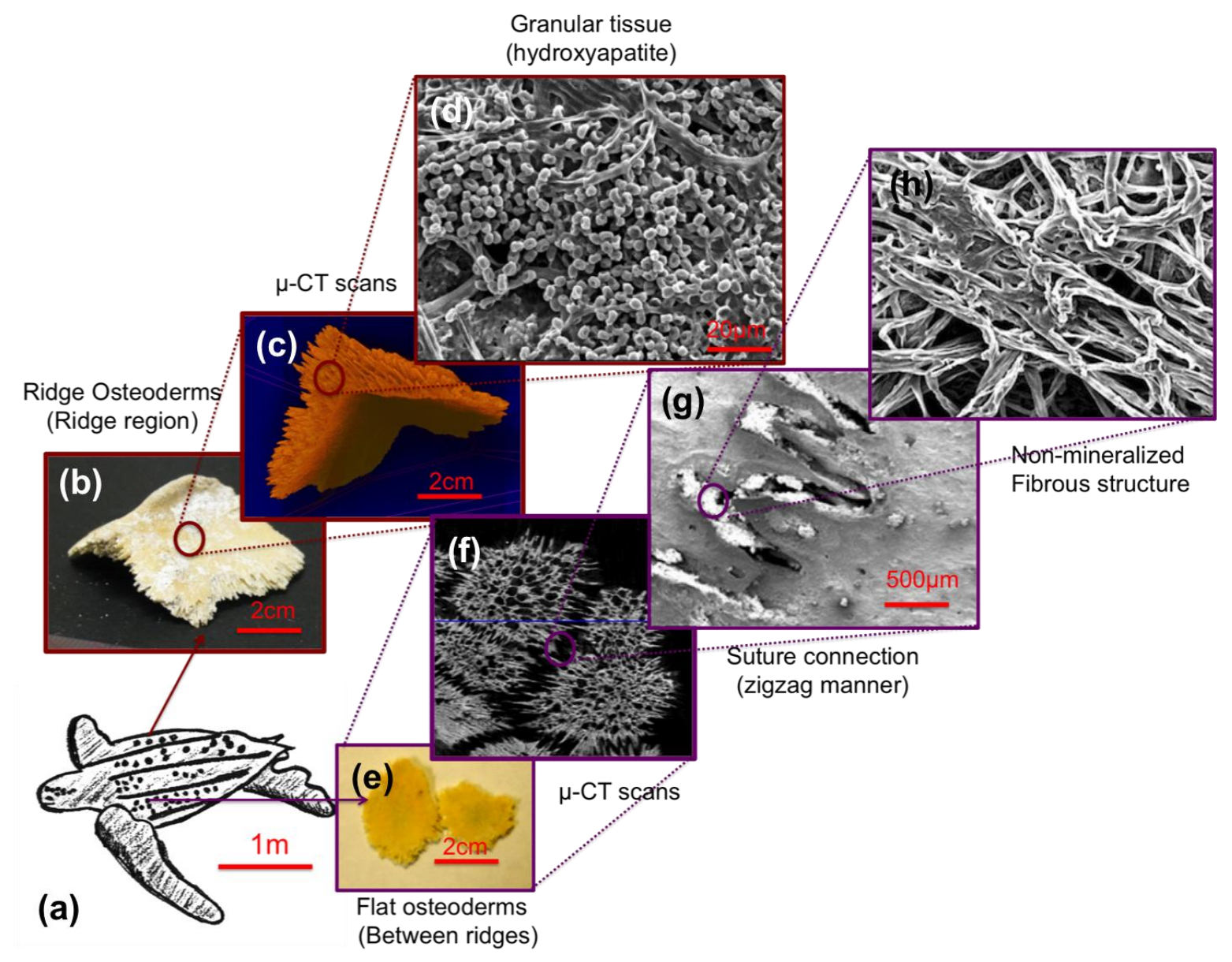

Figure 1: Multi-scale hierarchical structure of the (a) leatherback turtle shell with two types of osteoderms (flat and ridged); (b) osteoderm from the ridge portion (dorsal) of the animal with bony ridge; (c) micro-CT scan of the ridge osteoderm showing the individual standing out 3D sutures; (d) showing granular morphology under high magnification; (e) second type of osteoderm (flat) found on the dorsal and plastron region of the animal ; (f) micro-CT scan also indicating highly random porous morphology; (g) interconnecting suture design (zigzag manner) found between flat osteoderms; (h) fibrous collagen structure connecting the bony osteoderms. 


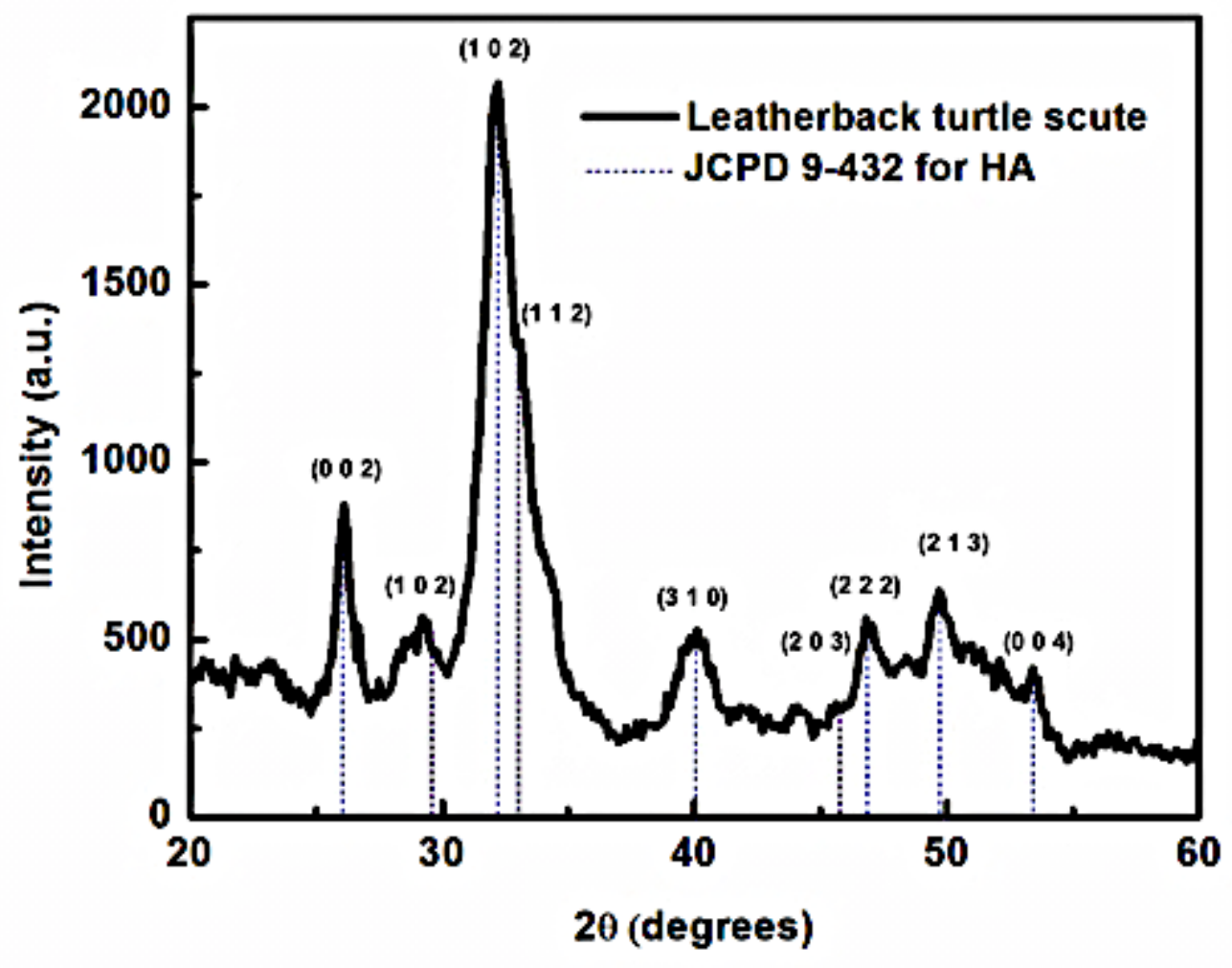

Figure 2: X-ray diffraction of leatherback sea turtle osteoderm; hydroxyapatite peaks (JCPD 9-432). 

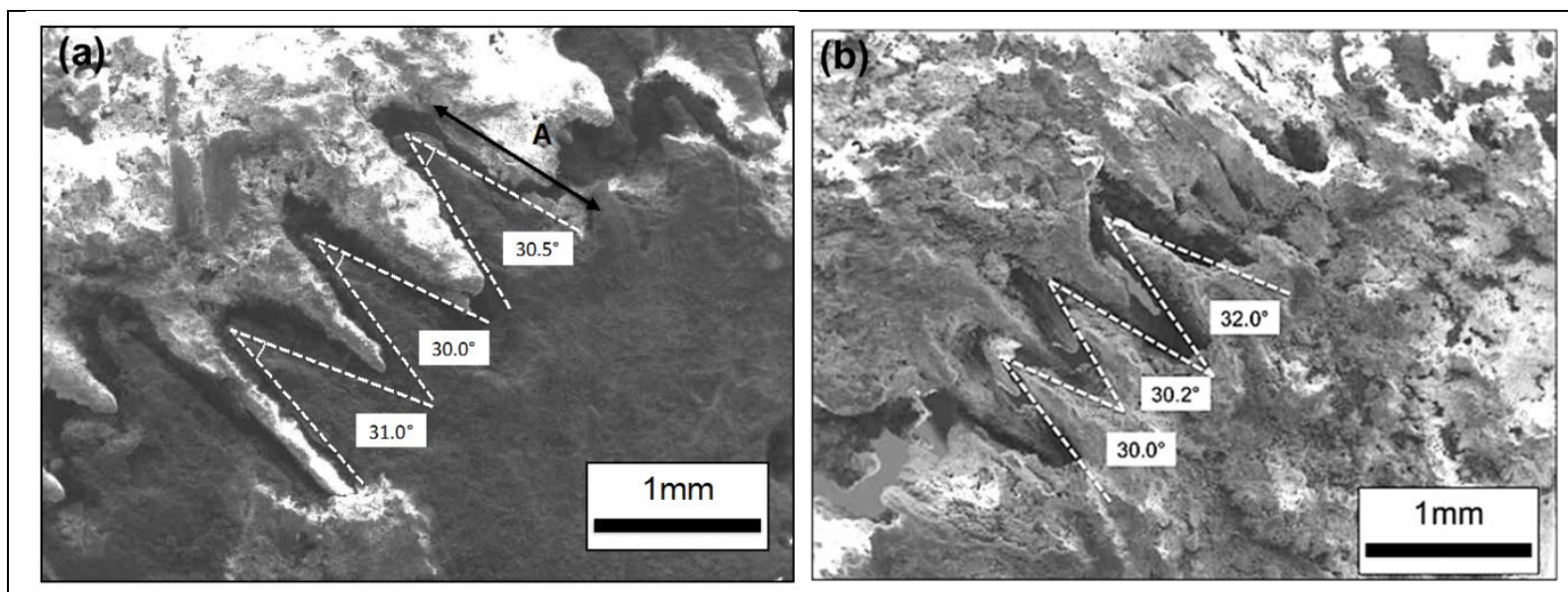

Figure 3: $(\mathrm{a}, \mathrm{b})$ Typical sutures between osteoderms; suture angles $2 \theta$ were marked and measured with an average of $\sim 30.24^{\circ}$ from 10 sample teeth; amplitude A (suture height) $\sim 0.6 \mathrm{~mm}$. 
(a)

(b)
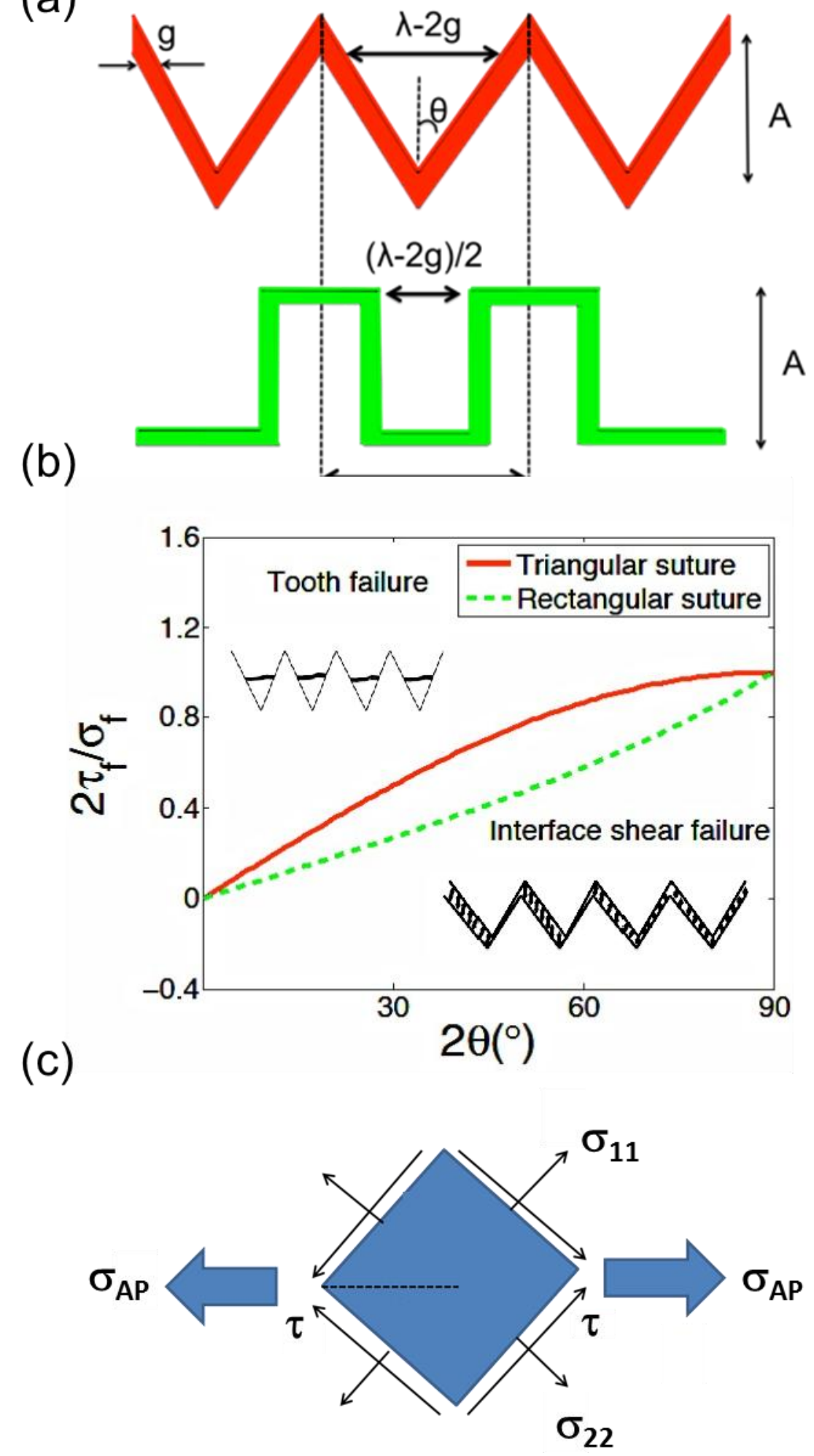

Figure 4: (a) Two suture geometries: (1) triangular (red) and (2) rectangular (green) teeth 
with suture angle $\theta$ shown. Amplitude A and wavelength $\lambda$ defined in plots. (b) $2 \tau_{f} / \sigma_{f}$ vs. $2 \theta$ is a ratio of shear stress to normal stress a function of material properties and $2 \theta$ for triangular (solid red) and rectangular (dashed green). The plot shows separated regions of "tooth failure" and "interfacial shear failure". The two distinct regions of tooth failure and interfacial shear failure are defined by the two curves: Triangular suture (red solid) and Trapezoidal Suture (green dashed). Due to the nature of the suture geometry, the triangular suture has a greater interfacial shear failure region than the Trapezoidal suture. (c) Normal and shear stresses produced by applied tensile stress $\sigma_{\mathrm{Ap}}$ at an angle $\theta$ corresponding to the orientation of tooth. 


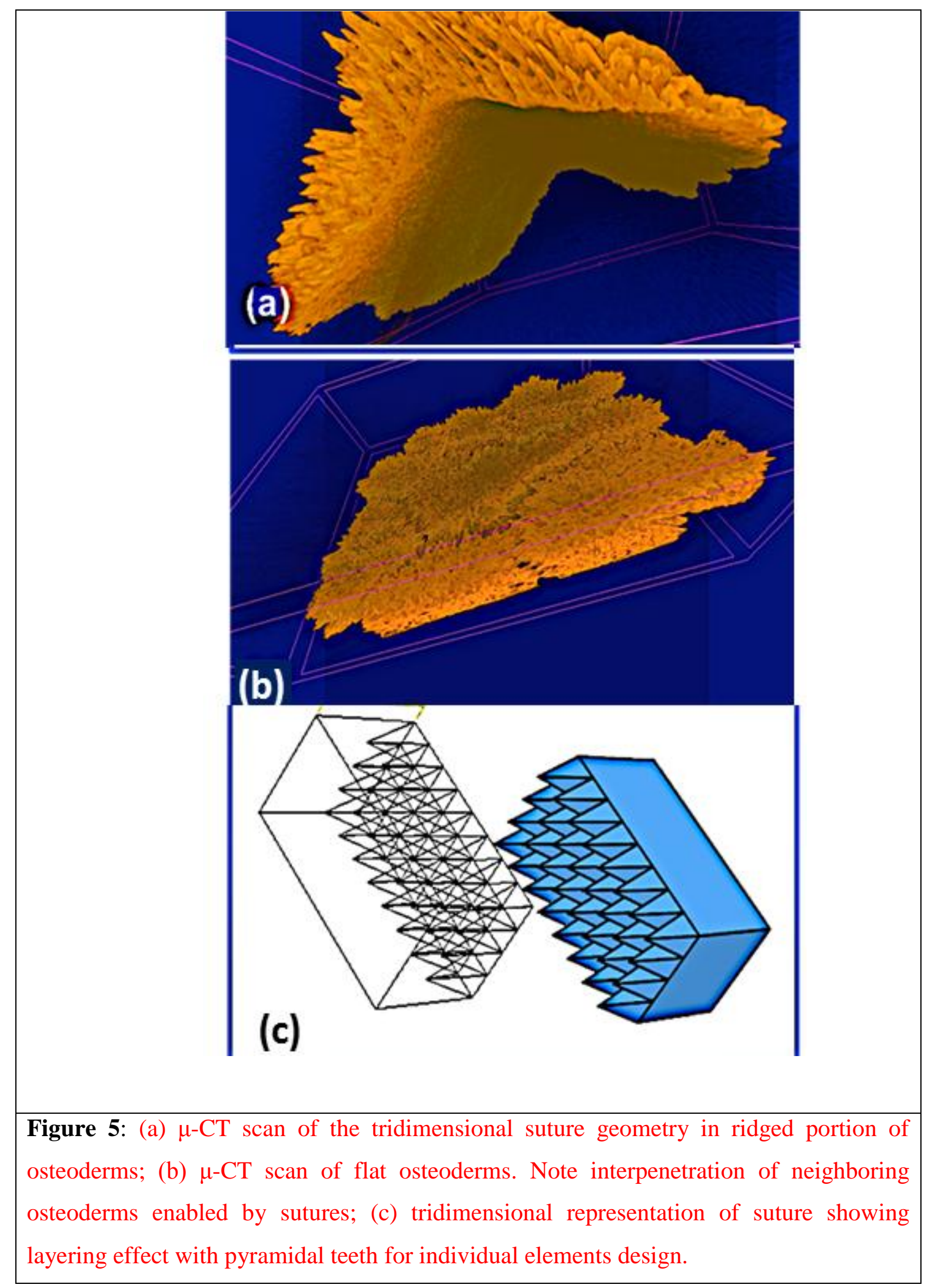




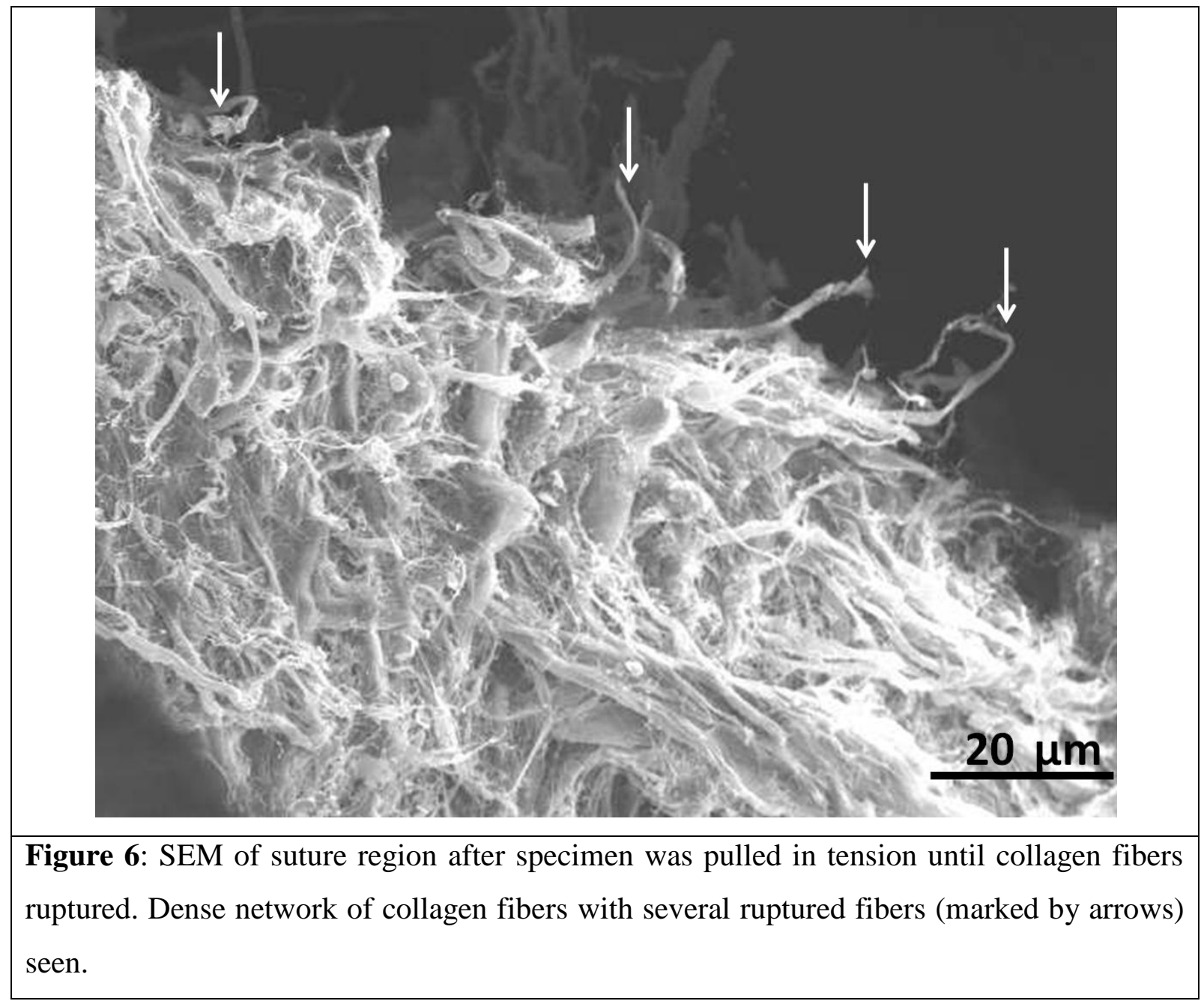




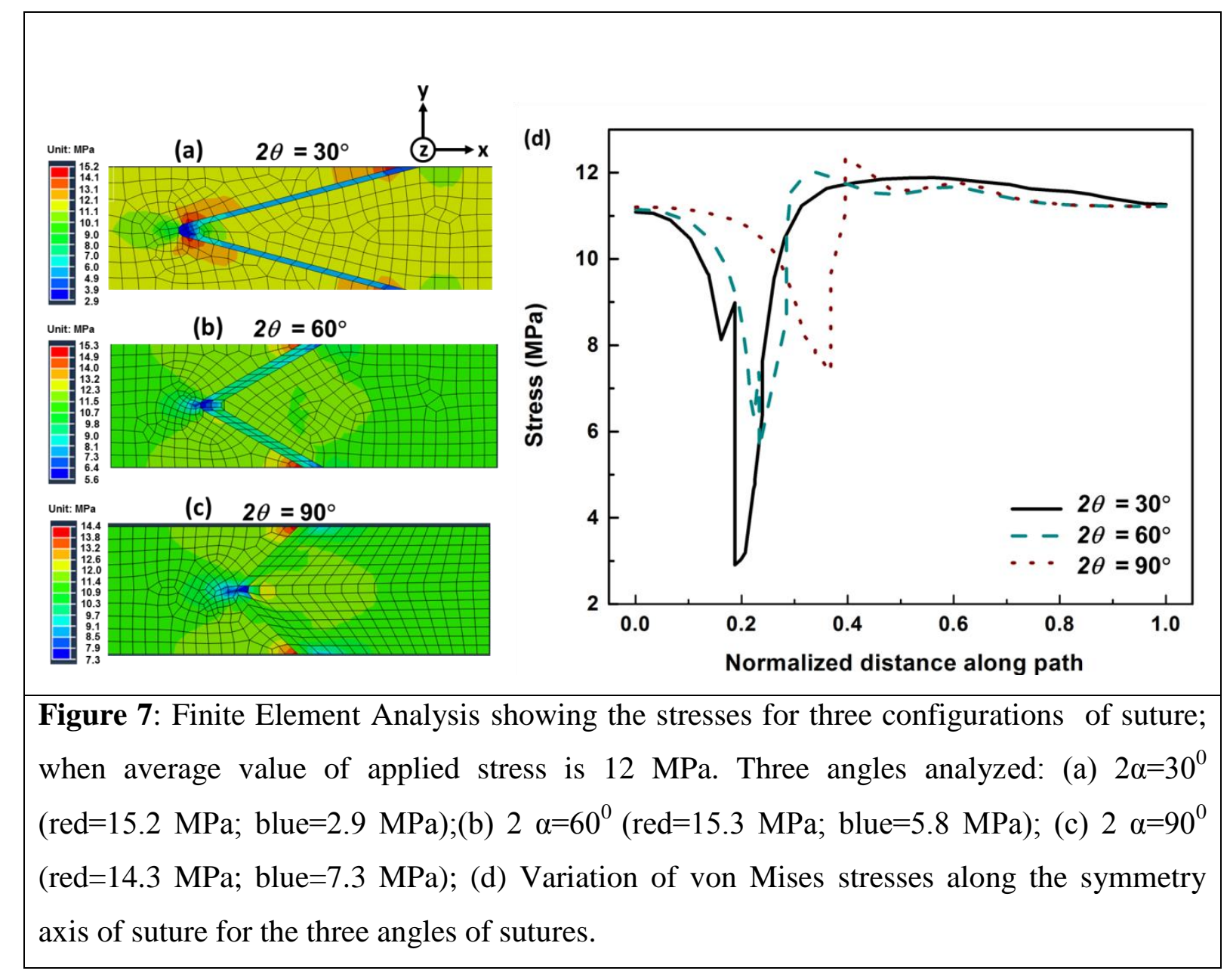




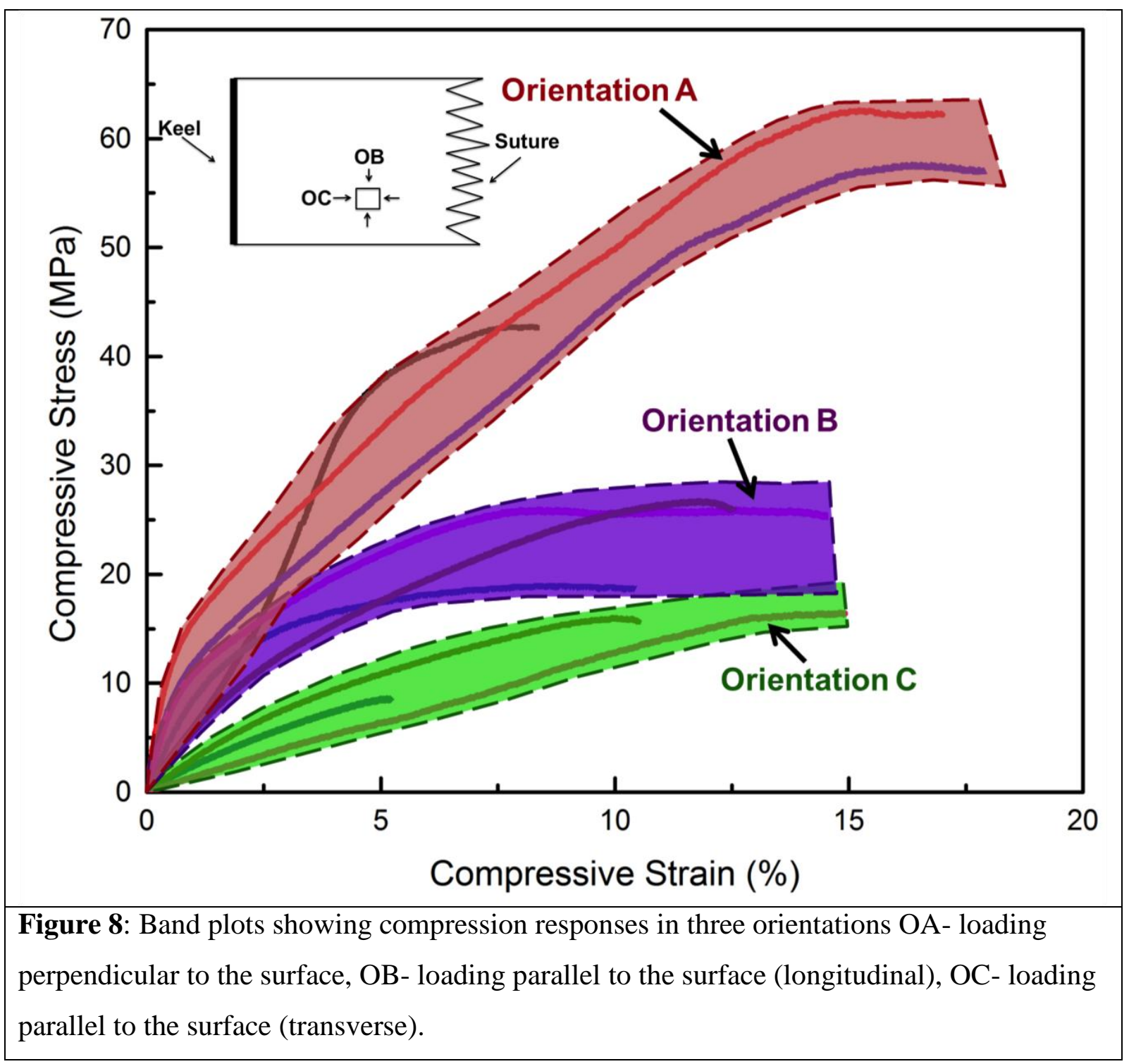




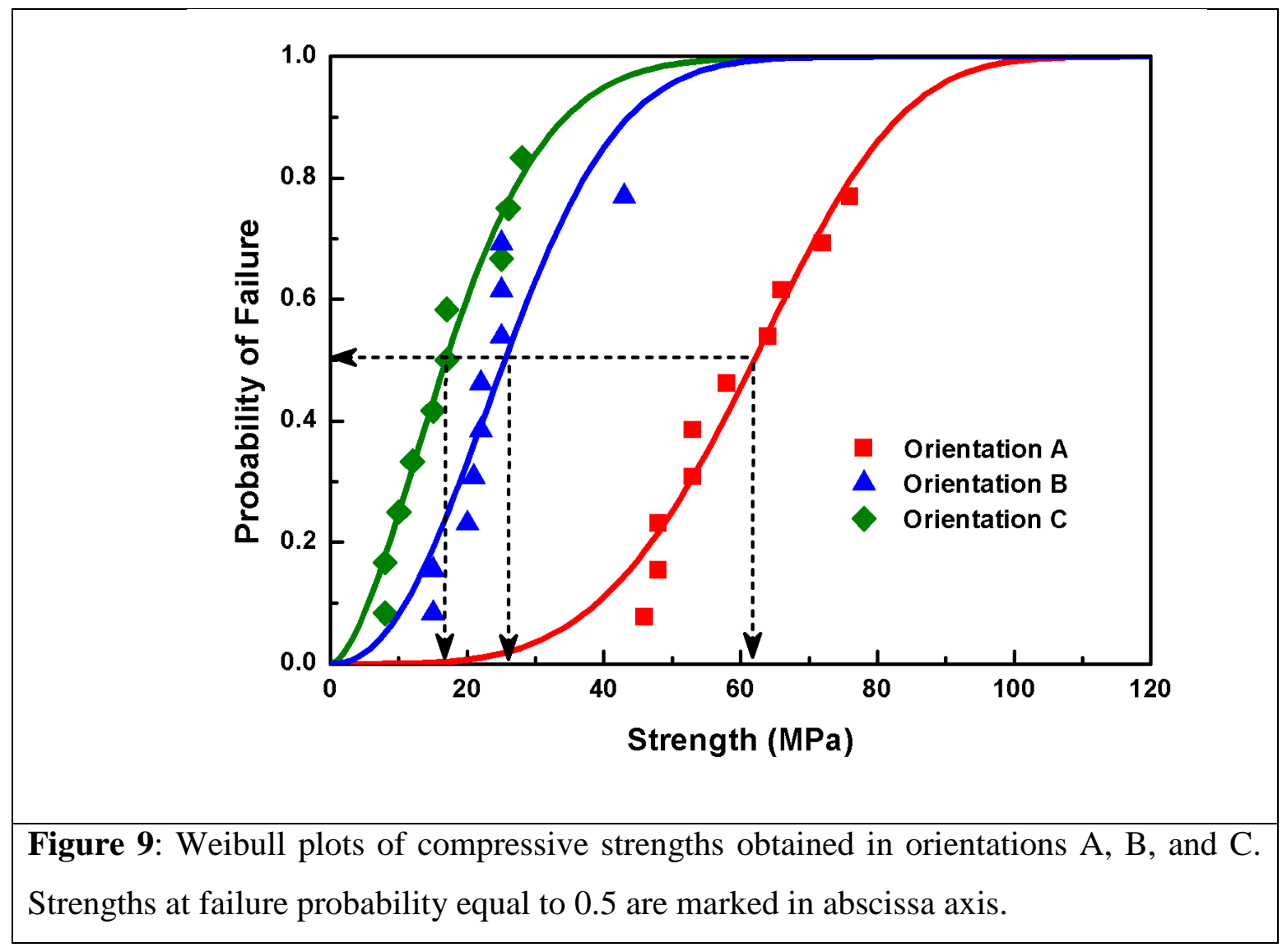




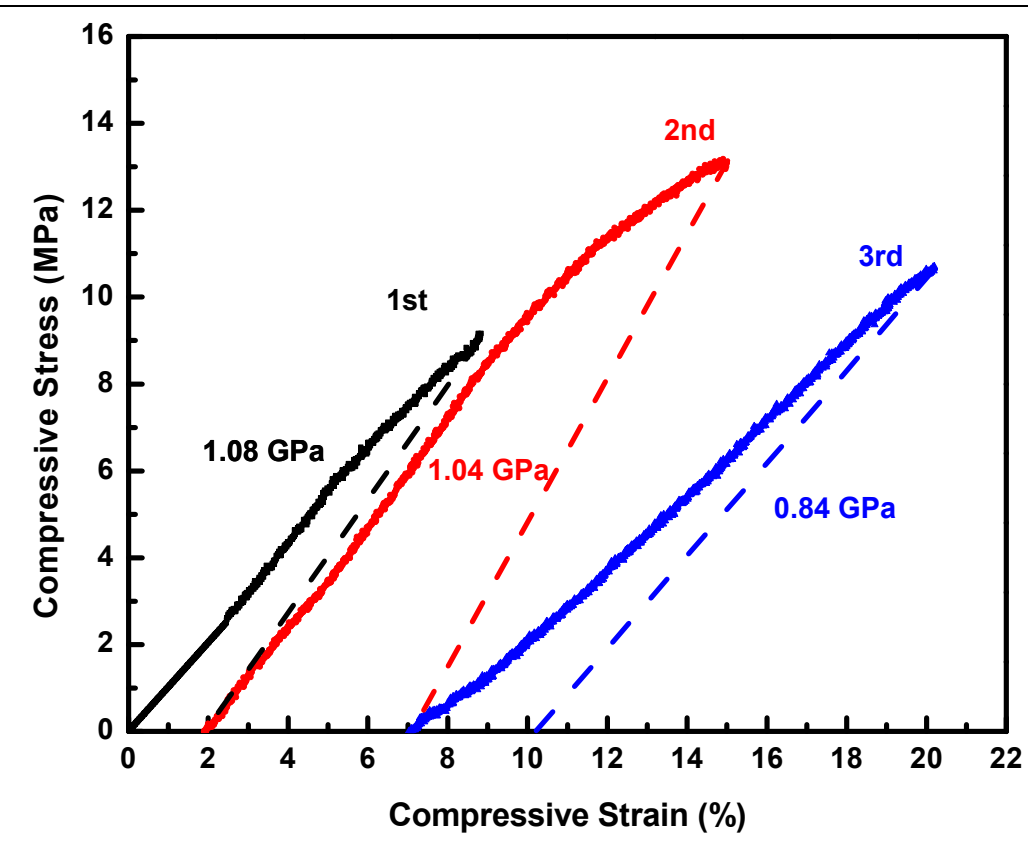

Figure 10: Compression results (loading-unloading-reloading) of wet samples tested in orientation A. While there is no significant stiffness change from $1^{\text {st }}$ to $2^{\text {nd }}$ compression cycle; there is a substantial decrease in stiffness upon $3^{\text {rd }}$ loading. This is attributed to damage evolution in the sample. This is a representative sequence. Several experiments were conducted. 


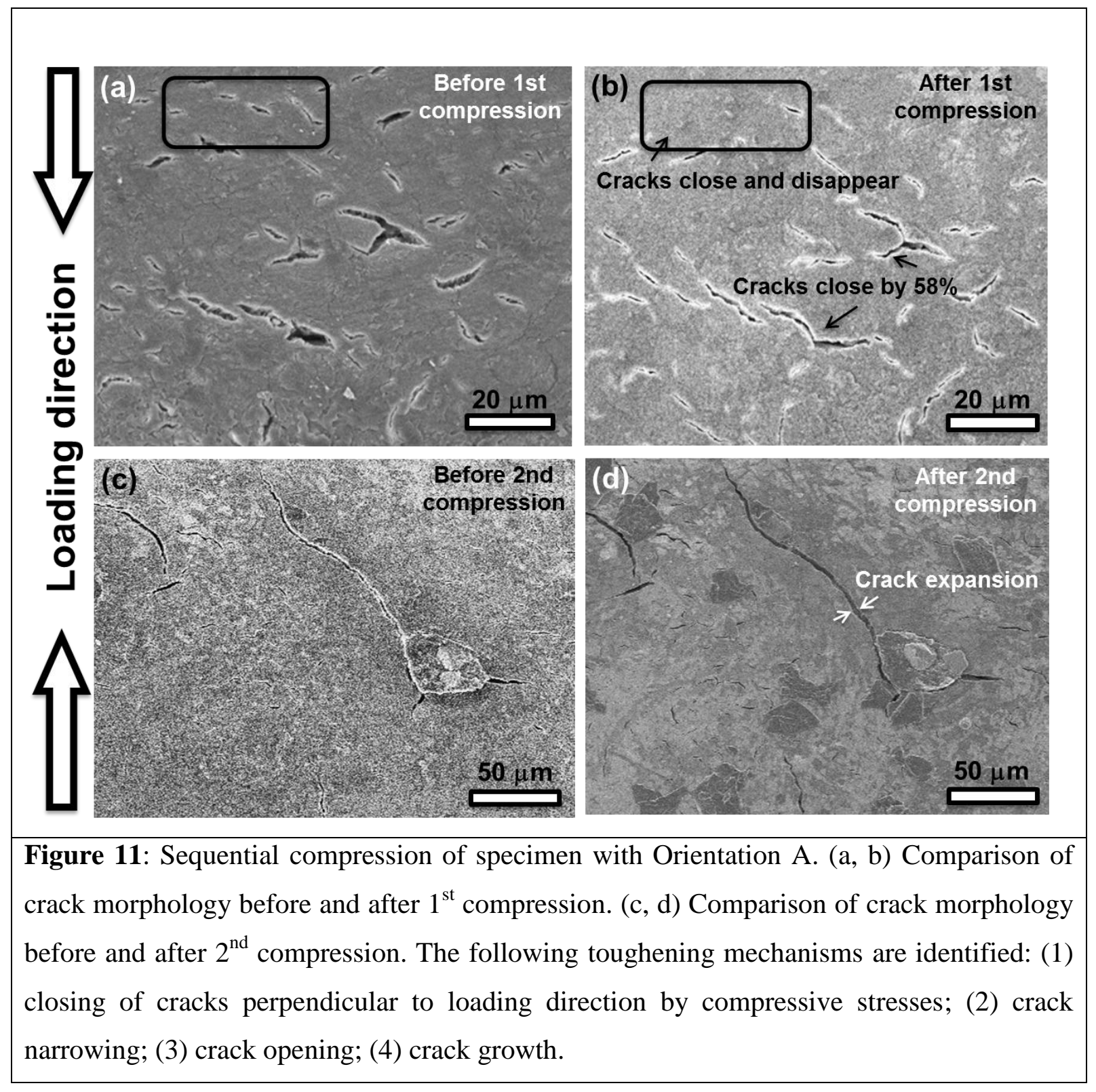


(a)

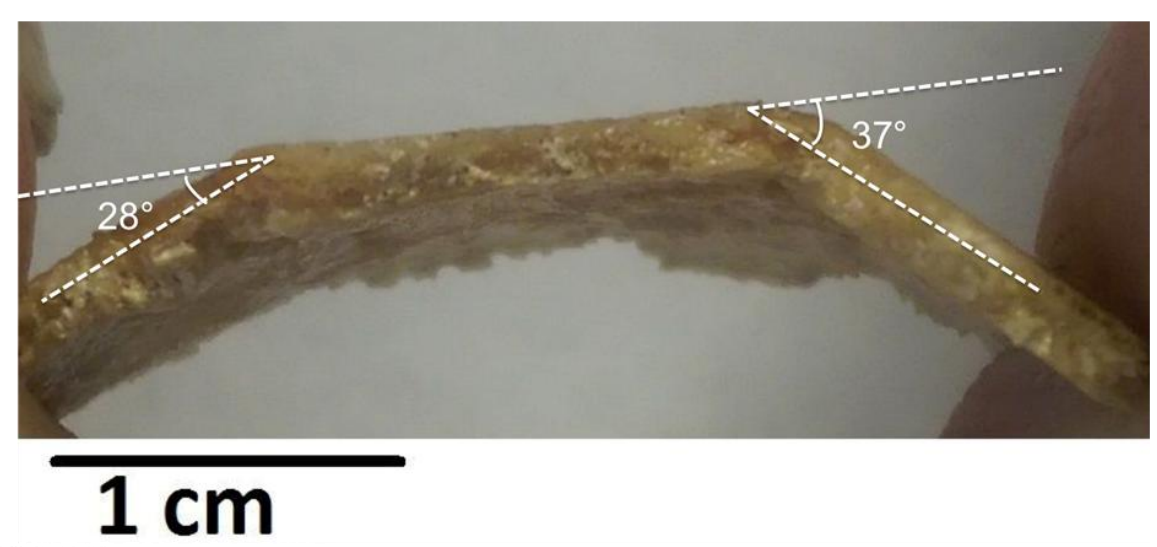

(b)

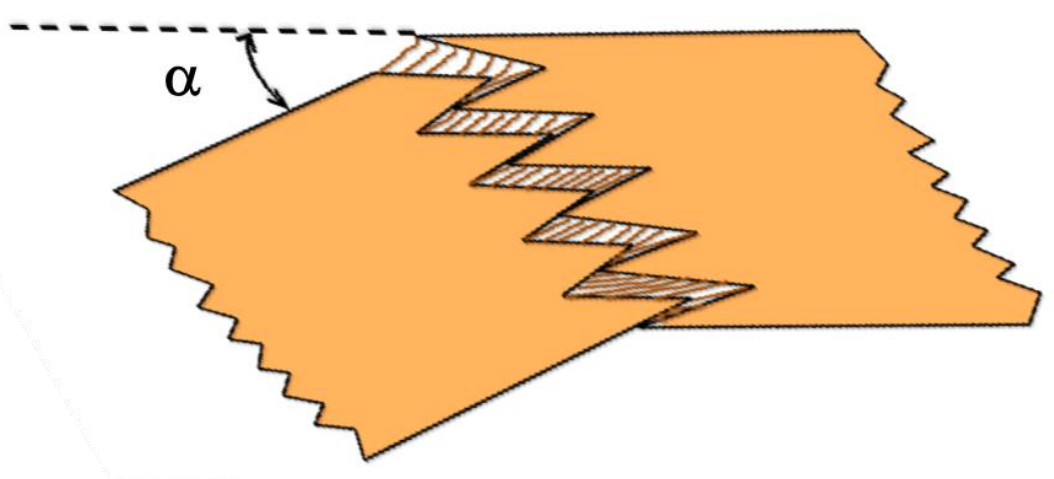

Figure 12: (a) Deformed segment of the plastron showing angles of deflection of $\alpha=28^{\circ}$ and $37^{\circ}$; (b) Schematic representation of lateral deflection with angle of $\alpha$ between two osteoderms; 
(a)

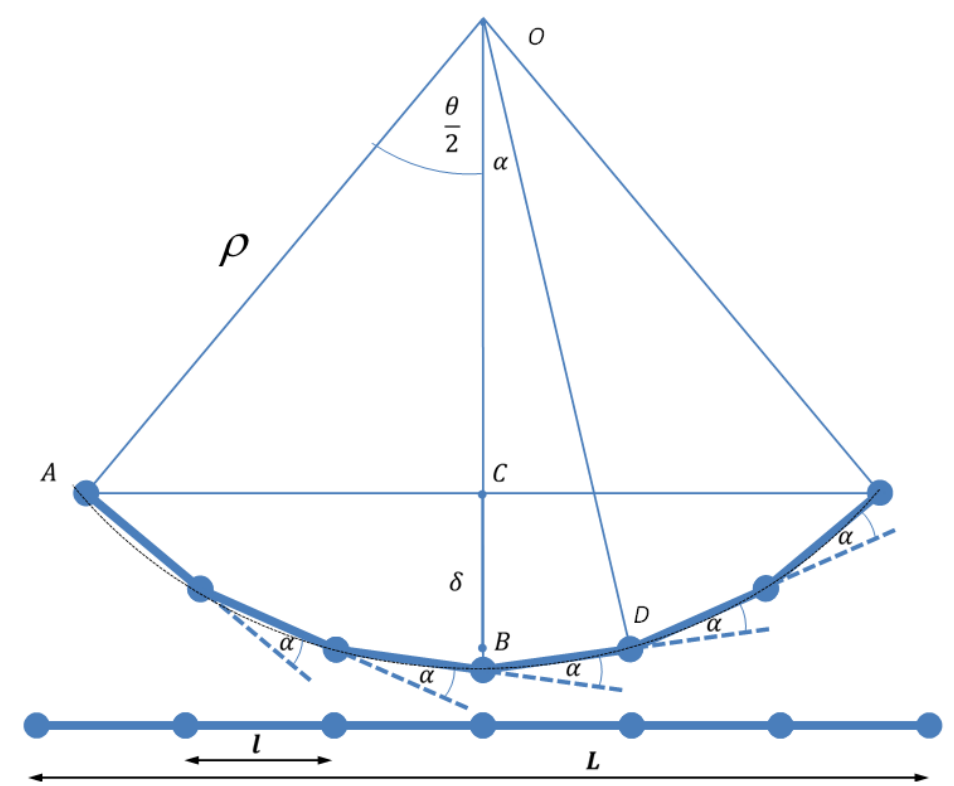

(b)

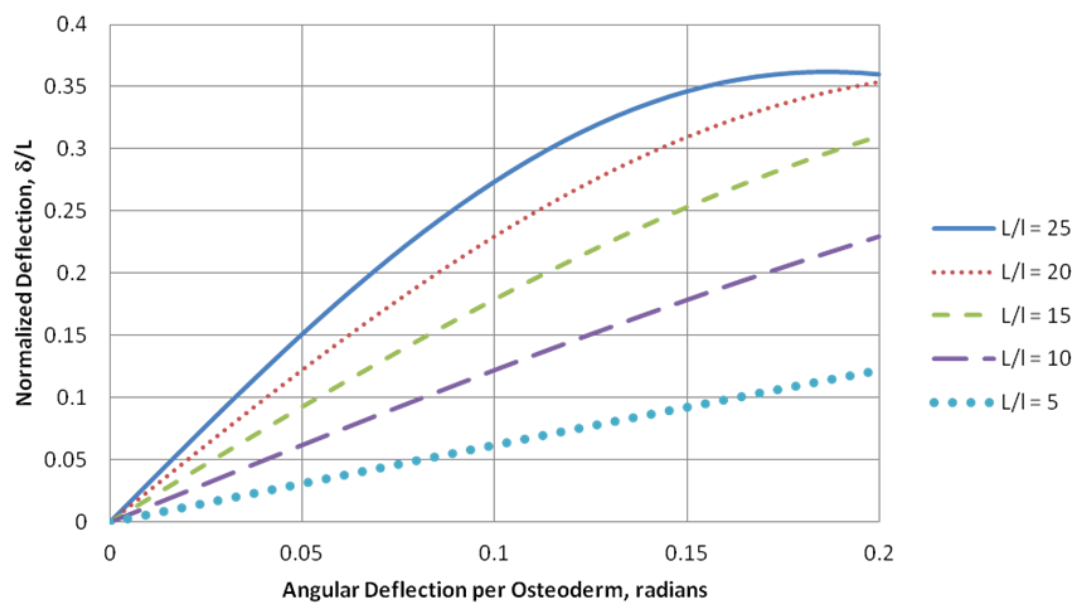

Figure 13: (a) Representation of total deflection $\delta$ in beam with length $L=n l$ assuming lateral angle $\alpha$ in each segment; (b) variation of the maximum deflection (normalized to length $L$ ) with angle $\alpha$ for five different values of $n=L / l: 5,10,15,20$, and 25 . 


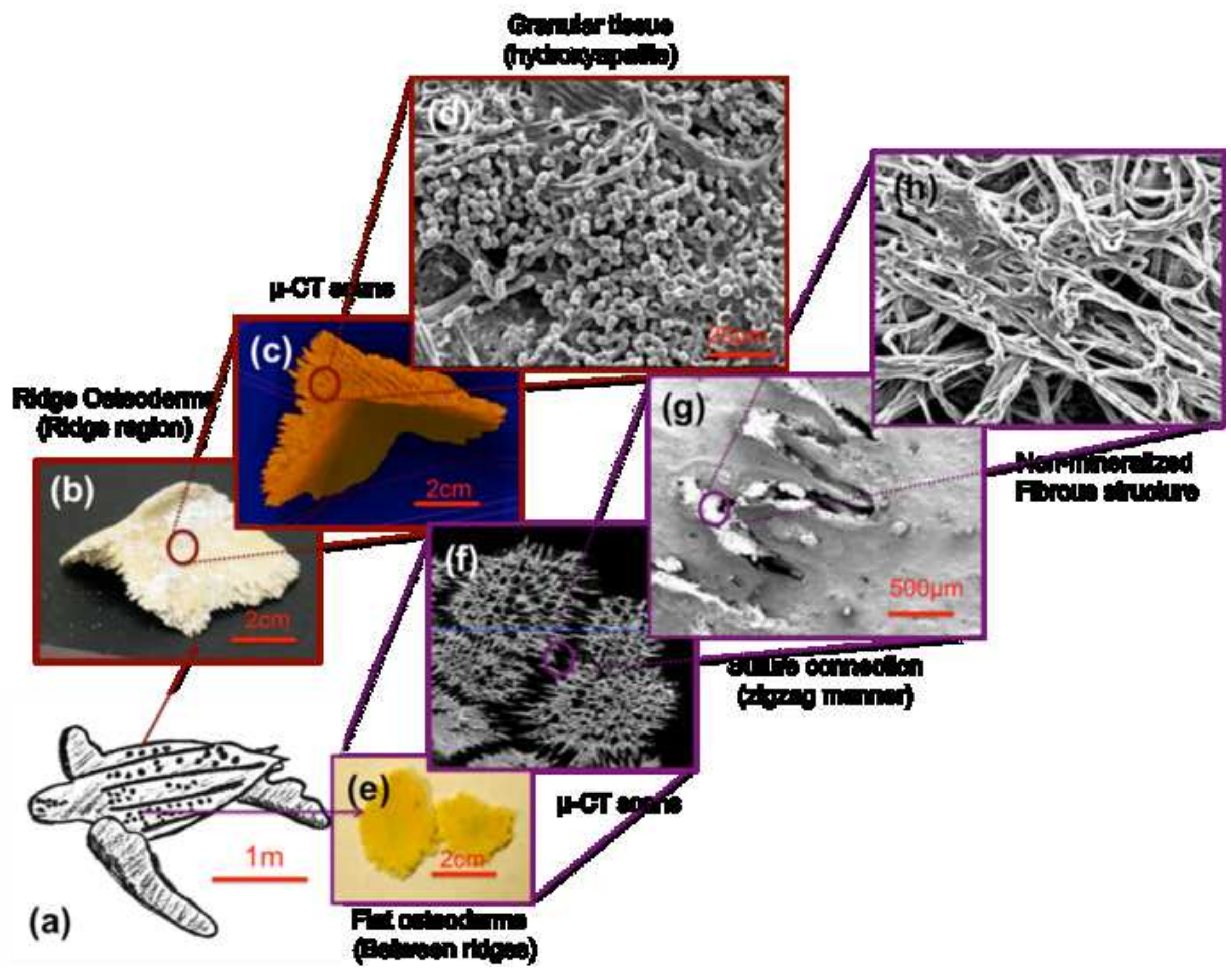

